\title{
Progress in Vaccine-Preventable and Respiratory Infectious Diseases-First 10 Years of the CDC National Center for Immunization and Respiratory Diseases, 2006-2015
}

\author{
Anne Schuchat, Larry J. Anderson, ${ }^{1}$ Lance E. Rodewald, Nancy J. Cox, Rana Hajjeh, ${ }^{2}$ \\ Mark A. Pallansch, Nancy E. Messonnier, Daniel B. Jernigan, Melinda Wharton
}

The need for closer linkages between scientific and programmatic areas focused on addressing vaccine-preventable and acute respiratory infections led to establishment of the National Center for Immunization and Respiratory Diseases (NCIRD) at the Centers for Disease Control and Prevention. During its first 10 years (2006-2015), NCIRD worked with partners to improve preparedness and response to pandemic influenza and other emergent respiratory infections, provide an evidence base for addition of 7 newly recommended vaccines, and modernize vaccine distribution. Clinical tools were developed for improved conversations with parents, which helped sustain childhood immunization as a social norm. Coverage increased for vaccines to protect adolescents against pertussis, meningococcal meningitis, and human papillomavirus-associated cancers. NCIRD programs supported outbreak response for new respiratory pathogens and oversaw response of the Centers for Disease Control and Prevention to the 2009 influenza $\mathrm{A}(\mathrm{H} 1 \mathrm{~N} 1)$ pandemic. Other national public health institutes might also find closer linkages between epidemiology, laboratory, and immunization programs useful.

$\mathrm{B}$ 2005, global spread of highly pathogenic avian influenza A(H5N1) (1), major disruption of US vaccine supplies (2), and anticipated introduction of multiple new vaccines, including those targeting emerging drug-resistant respiratory infections, provided a rationale for the Centers for Disease Control and Prevention (CDC) to establish the National Center for Immunization and Respiratory Diseases (NCIRD). A closer linkage between science and program was an explicit goal of the center's formation, and

Author affiliation: Centers for Disease Control and Prevention, Atlanta, Georgia, USA

DOI: https://doi.org/10.3201/eid2407.171699
NCIRD has been on the cutting edge of applying advances in technology to public health. In April 2006, the new center brought scientific units responsible for epidemiologic and laboratory aspects of most vaccine-preventable and other acute respiratory infectious diseases together with programs supporting public sector immunization. The center's activities aligned to address 8 initial strategic priorities (Table 1).

NCIRD concentrated the expertise of the agency on the viral and bacterial agents that cause pneumonia, influenza, and other acute respiratory syndromes; responsibilities for tuberculosis remained elsewhere (online Technical Appendix, https://wwwnc.cdc.gov/EID/article/24/7/17-1699Techapp1.pdf). The expanded list of newly vaccine-preventable diseases meant response in areas traditionally managed by communicable disease units relied on immunization expertise, and the newer vaccines in turn required enhanced laboratory-based surveillance for accurate postlicensure evaluations. The mission of NCIRD was to prevent disease, disability, and death through immunization and control of respiratory and related infectious diseases. The center embedded field staff within and provided funding and technical assistance to state, local, and territorial health departments to strengthen detection, prevention, and control of these conditions, with particular emphasis on childhood immunization, influenza, and emerging respiratory infectious disease threats. The center also housed several World Health Organization (WHO) International Collaborating Centers and provided leadership for global laboratory networks for influenza, polio, measles, rotavirus, and bacterial meningitis, among others.

\footnotetext{
${ }^{1}$ Current affiliation: Emory University, Atlanta, Georgia, USA.

${ }^{2}$ Current affiliation: World Health Organization, Cairo, Egypt.
} 
Table 1. Strategic priorities for the National Center for Immunization and Respiratory Diseases, Centers for Disease Control and Prevention

Strategic priorities

Improve immunization programs

Implementation examples

Implemented central vaccine distribution and Vaccine Tracking

System (VtrkS); supported development of adolescent platform for vaccination

Strengthen systems to evaluate policy effectiveness

Initiated annual estimation of influenza vaccine impact based on

influenza surveillance, vaccine effectiveness studies, and

immunization coverage surveys; introduced National Immunization Survey-Teen and quality standards for systems monitoring schoolbased immunization coverage

Accelerate vaccine-preventable disease reduction worldwide

Implementing partner for the Hib Initiative (2005-2009), which facilitated decisions to introduce Haemophilus influenzae b (Hib)containing vaccine in all Global Alliance for Vaccines and Immunization-eligible countries and provided model framework for subsequent new vaccine introduction efforts

Reduce complications of pneumonia and influenza

Improve pandemic preparedness

Strengthen response to respiratory outbreaks

Develop and promote strategies to reduce respiratory infections, vaccine-preventable diseases, and control antimicrobial resistance

Improve identification of causes of respiratory infections

During the subsequent decade, NCIRD established strong evaluation systems to measure policy and program impacts. NCIRD also spearheaded modernization of the nation's immunization activities and collaborated with other infectious disease programs to invest in advanced molecular detection technology to accelerate prevention, detection, and control of influenza and other respiratory threats. The center aimed to sustain the public's acceptance of vaccination while providing technical assistance and on-the-ground support for outbreak responses to previously rare vaccine-preventable diseases. In 2009, the staff of NCIRD led the response of CDC to the first influenza pandemic of the 21 st century. In subsequent years, response of NCIRD to other novel respiratory threats, such as Middle East respiratory syndrome coronavirus, severe respiratory illness associated with enterovirus D68, and increases in Legionnaires' disease, involved collaboration with clinicians, state, and local health departments and, when appropriate, international organizations and ministries of health.

\section{Immunization System Change at CDC and Health Departments}

During 2005-2015, the childhood immunization schedule expanded substantially, with corresponding increased costs (Figure 1), sustained high immunization coverage of traditional vaccines, and increased coverage of newer vaccines (Figure 2). Licensure of several vaccines and
Issued evidence-based guidance for influenza antiviral use to reduce severity of influenza illness

Enhanced laboratory detection of novel influenza viruses and led response to first influenza pandemic of the 21st century

Developed Unexplained Respiratory Disease Outbreak tool kit for state, local, and international partners

(https://www.cdc.gov/urdo/index.html)

Expanded the Advisory Committee on Immunization Practices recommendations for annual influenza vaccination and age groups recommended for pneumococcal conjugate vaccination; incorporated Get Smart: "know when antibiotics work" activities into national strategy to reduce antimicrobial resistance

Validated TaqMan technology for multiple pathogen diagnosis of respiratory syndromes; completed multicenter studies of etiology of pneumonia in the community in adults and children

shifting epidemiology in selected vaccine-preventable diseases placed a premium on strong surveillance and evaluation systems to provide evidence needed for policy. The Advisory Committee on Immunization Practices (ACIP) released numerous recommendations during this period (Table 2). Clinicians developed an adolescent platform to permit delivery of vaccines to children 11-12 years of age. The program introduced the National Immunization Survey-Teen (a large telephone survey of parents, with healthcare provider verification of records) in 2006 to monitor coverage of immunizations in persons 13-17 years of age. Expanded monitoring of influenza vaccine coverage relied on several new techniques, including leveraging hospital reporting to the Center for Medicare and Medicaid Services, which incentivized reporting of influenza vaccination of healthcare workers.

Monitoring of vaccine performance resulted in updates to vaccine recommendations. Continued varicella outbreaks led to recommendation of a second dose of varicella-containing vaccine. Emergence of waning immunity following meningococcal conjugate vaccine (Men ACWY) prompted recommendation for a booster dose. Resurgence of pertussis prompted investigations of vaccine performance and characterization of circulating strains. Surveillance detected emergence of pertactin-deficient Bordetella pertussis and epidemiologic studies documented the limited duration of protection afforded by acellular vaccines (3). Accordingly, updated tetanus, diphtheria, and acellular 


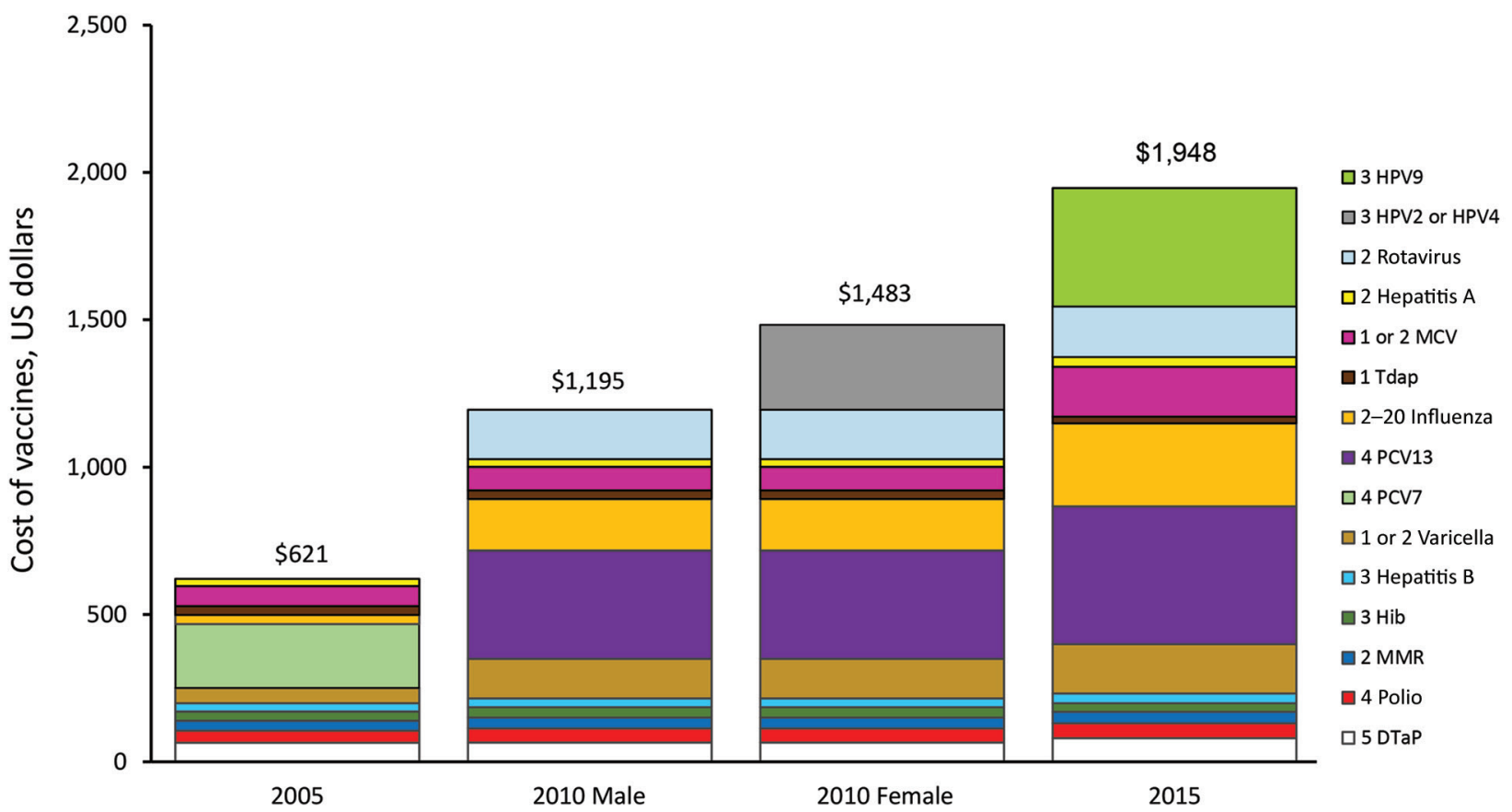

Figure 1. Cost of vaccines routinely recommended from birth through 18 years of age, according to public sector contract prices, United States, 2005, 2010 (by sex), and 2015. Values in key indicate no. vaccinations/series. Data were based on federal contract prices as of September 1, 2005; April 6, 2010; and April 1, 2015. DTaP, diphtheria, tetanus, and acellular pertussis vaccine; Hib, Haemophilus influenzae type b vaccine; HPV, human papillomavirus vaccine; MCV, meningococcal conjugate vaccine; MMR, measles, mumps, and rubella vaccine, PCV, pneumococcal conjugate vaccine; Tdap, tetanus, diphtheria, and acellular pertussis vaccine.

pertussis vaccine recommendations advised women to receive this vaccine during each pregnancy to prevent severe disease in early infancy.

NCIRD implemented changes that modernized the nation's immunization infrastructure and strengthened the program's efficiency. Establishment of a centralized vaccine distribution system in 2008 eliminated $99 \%$ of the 430 vaccine depots that states previously relied on to store vaccines, resulting in direct shipping to $>40,000$ provider sites, with reduced inventory costs and waste. NCIRD replaced a DOS-based vaccine ordering and management system with the vaccine tracking system VtrkS (https://www.cdc.gov/ vaccines/programs/vtrcks/index.html), an SAP-enabled data management and analytic system (https://www.sap. $\mathrm{com} /$ products/data-services.html), thereby improving the accountability of the CDC multibillion-dollar vaccine supply chain. Improvements in immunization information systems (i.e., registries) have been slowed by diversity of registries in states; barriers to interstate data sharing; and incomplete records, particularly for adult vaccinations. Investments focused on increasing their interoperability with electronic medical records, expanding physician use, developing clinical decision support tools (e.g., prompts for which vaccine doses are due or overdue), and improving efficiency and accuracy of data entry.
Provisions of the Affordable Care Act of 2010 regarding prevention services required updated insurance plans to include all vaccines routinely recommended by the ACIP without copayments when administered by an in-network provider. The Vaccines for Children Program, implemented in 1994, provides free vaccines for children who are either uninsured or Medicaid eligible, among others (http://www.cdc.gov/vaccines/programs/vfc/index.html). By requiring first dollar coverage for ACIP-recommended vaccines, the Affordable Care Act provision eliminated most out-of-pocket costs for persons with either public or private insurance. A notable exception occurs for vaccines covered under Medicare part D (e.g., shingles), for which senior citizens might still have large out-of-pocket expenditures. NCIRD helped health departments establish billing systems so that insurance companies paid for vaccines given to their covered members, saving limited public sector resources (https://www.cdc.gov/vaccines/programs/ billables-project/success-stories.html).

Protecting the infrastructure supporting immunization was essential during the decade, even once most insurance plans fully covered vaccination (4). State, local, and federal immunization programs responded to resurgent pertussis; outbreaks of measles, mumps, and meningococcal meningitis; extended shortages of Haemophilus influenzae 
Figure 2. Selected immunization coverage by vaccine and target group, United States, 2005-2006 and 2015. PCV7 and PCV13 are $\geq 4$ doses. Rotavirus coverage is 2 or 3 doses depending on product. PCV7 is a pneumococcal conjugate vaccine with 7 serotypes, and PCV13 is a pneumococcal conjugate vaccine with 13 serotypes. Data were obtained from the National Immunization Survey for toddlers, the National Immunization Survey-Teen (NIS-Teen) for adolescents, the National Immunization Survey-Flu for influenza, and the National Health Interview Survey for PPSV and zoster. DTaP,

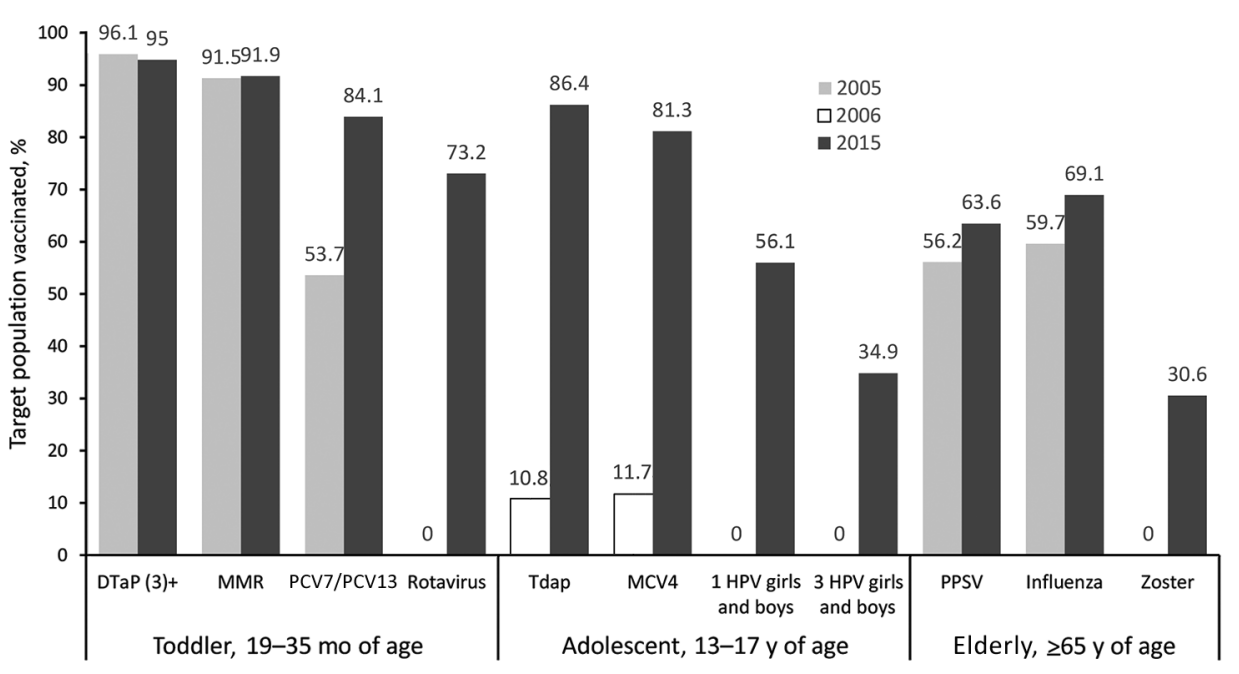
diphtheria, tetanus, and acellular pertussis vaccine; HPV, human papillomavirus vaccine; MCV, meningococcal conjugate vaccine; MMR, measles, mumps, and rubella vaccine; PCV, pneumococcal conjugate vaccine; PPSV, pneumococcal polysaccharide vaccine; Tdap, tetanus, diphtheria, and acellular pertussis vaccine.

type $\mathrm{b}$ (Hib) conjugate, and 5-in-1 infant combination vaccines. Enhancements made at the national level included randomly sampling cellular telephones and land lines to access participants for the National Immunization Survey (5), and strengthening the link between pediatric immunization caregivers, oncologists, and cancer survivor advocates in an effort to improve human papillomavirus vaccination of children 11 and 12 years of age (https://www.cancer.org/ health-care-professionals/national-hpv-vaccination-roundtable.html).

Sustaining high levels of vaccine acceptance was also a focus. Based on formative research with parents and clinicians, and in partnership with the American Academy of Pediatrics, NCIRD released a communication tool kit aimed at promoting effective vaccine conversations between providers and parents. CDC enhanced transparency of the ACIP process by introducing Grading of Recommendations Assessment, Development and Evaluation for systematic review of the evidence (6), and webcast the committee's public meetings (7). Although vaccinating children remained a social norm during this period, with $<1 \%$ of toddlers receiving no vaccine doses $(8)$, outbreaks of measles identified geographic areas where personal belief exemptions were becoming more common $(9,10)$.

On the occasion of the 20th anniversary of implementation of the Vaccines for Children program, CDC staff

Table 2. Selected recommendations of the Advisory Committee on Immunization Practices, Centers for Disease Control and Prevention, 2005-2015*

\begin{tabular}{lc}
\hline New vaccine (indication) & Date of ACIP recommendation \\
\hline Meningococcal ACWY conjugate (adolescents) & 2005 Feb \\
Tdap (adolescents) & 2005 Jun \\
Measles, mumps, rubella, and varicella (MMRV) & 2005 Oct \\
Influenza (24-59-month-old children) & 2006 Feb \\
Rotavirus (infants) & 2006 Feb \\
Human papillomavirus (adolescent girls) & 2006 Jun \\
Second-dose varicella & 2006 Jun \\
Zoster (shingles) & 2006 Oct \\
Influenza (persons 6 mo-18 y of age) & 2009 Feb \\
13-valent pneumococcal conjugate vaccine (children) & 2010 Feb \\
Influenza (universal in persons >6 mo of age) & 2010 Feb \\
Second dose of meningococcal ACWY conjugate (adolescents) & 2010 Oct \\
Human papillomavirus (adolescent boys) & 2011 Oct \\
Tdap (in every pregnant woman) & 2012 Oct \\
$13-v a l e n t$ pneumococcal conjugate vaccine (persons $\geq 65$ years of age) & 2014 Aug \\
Meningococcal B vaccine (during outbreaks and in high-risk persons) & 2015 Feb \\
HPV-9 (adolescents) & 2015 Feb \\
Meningococcal B (adolescents, category B) & 2015 Jun \\
\hline
\end{tabular}

*ACIP, Advisory Committee on Immunization Practices; HPV, human papillomavirus; Tdap, tetanus, diphtheria, and acellular pertussis. 
completed analyses of the impact of childhood immunization. Twenty years of childhood immunization, at actual coverage levels, averted 322 million illnesses and 732,000 premature deaths, at a net savings of $\$ 295$ billion in direct costs and $\$ 1.38$ trillion in total societal costs (11). The childhood immunization series was estimated to save $\$ 3$ in direct medical costs for each dollar invested (12).

\section{Improving Prevention and Control of Respiratory Infections}

Substantial improvements in control of respiratory infections in the United States occurred during the decade. Scientists in industry and academia have advanced molecular detection for respiratory pathogens during this period, and NCIRD staff capitalized on advancements to apply tools to the public health need for detection of respiratory infections (13), thereby extending their value beyond commercial or clinically relevant applications. NCIRD applied new multipathogen diagnostic tests to characterize the burden of community-acquired pneumonia in the United States (13-15) and collaborated on similar efforts in developing country settings $(16,17)$.

Hospitalizations and deaths from respiratory infectious disease in the United States continued to decrease during this period. Pneumonia and influenza decreased from the sixth to eighth leading cause of death in the United States during 2006-2015, and age-adjusted mortality rates decreased by $17.4 \%$, from 18.4 deaths $/ 100,000$ persons in 2006 to 15.2 deaths $/ 100,000$ persons in 2015 (18). Severe influenza seasons contributed to variability in influenza hospitalizations, but pneumonia hospitalizations decreased by $11.7 \%$, from $1,781,137$ in 2006 to $1,571,428$ in 2014 (Figure 3).

Several advances probably contributed to the decrease in all-cause pneumonia hospitalizations. Pediatric use of pneumococcal conjugate vaccine (PCV) averted an estimated 47,000 (43\%) hospitalizations in children $<2$ years of age and 168,000 pneumonia hospitalizations in all age groups by 7-9 years after introduction of 7-valent PCV (PCV7) vaccine (19). Although increases in drug-resistant nonvaccine serotype invasive pneumococcal disease occurred, an expanded serotype formulation, a 13-valent pneumococcal conjugate vaccine (PCV13), replaced PCV7 in 2010. The Active Bacterial Core surveillance of the Emerging Infections Program Network conducted studies of serotype-specific changes in invasive pneumococcal disease during the decade, which suggest that much of the decrease in adult pneumococcal illness was caused by reduced transmission of vaccine-type pneumococci from vaccinated children to adults (20). In addition, highly active antiretroviral therapy reduced the extremely high risk for pneumonia among persons infected with HIV and likely lowered all-cause pneumonia burden in this population (21).

Given the higher risk for invasive pneumococcal disease associated with active and passive cigarette smoke, reductions in cigarette smoking among adults and in secondhand smoke exposure during this period might also have reduced pneumonia (22-24). Annual vaccination rates against seasonal influenza among adults $\geq 65$ years of age increased from $59.7 \%$ in 2005 to $69.1 \%$ in 2015 (25), and vaccination rates among other age groups, especially children, increased substantially. In August 2014, PCV13 was recommended for persons $\geq 65$ years of age, in addition to the longstanding recommendation for 23-valent pneumococcal polysaccharide vaccine (26). Quantifying the independent role any of these factors played in the decrease in hospitalizations and deaths would be difficult.

During this period, program monitoring focused on strengthening the link between data and action. NCIRD collaborations sped up the availability of data on influenza vaccine coverage and effectiveness. Interim estimates of early vaccine coverage were released each December for

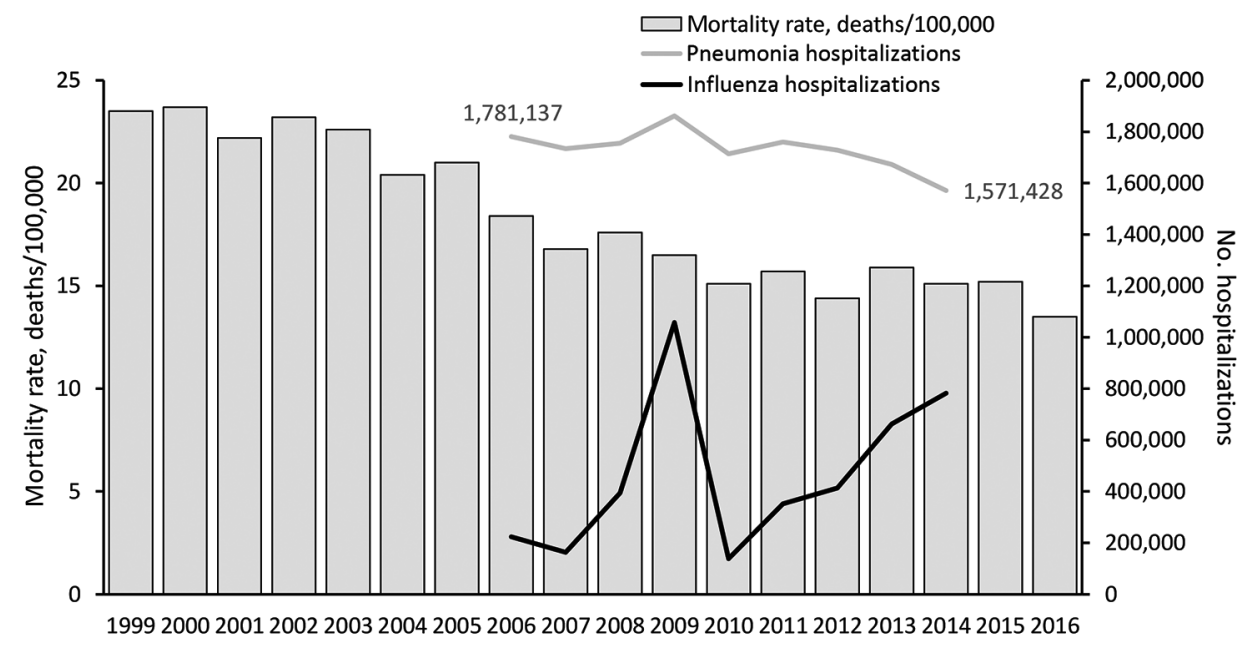

Figure 3. Pneumonia and influenza mortality rates and hospitalization counts by year, United States, 1999-2016. Age-adjusted mortality rates were obtained from the National Center for Health Statistics and based on underlying cause of death; nationwide hospitalization estimates were obtained from the Agency for Healthcare Research and Quality Healthcare Cost and Utilization Project. 
Progress in First 10 Years of the CDC NCIRD

the ongoing influenza season, and preliminary estimates of the effectiveness of the influenza vaccine for that season were disseminated during the first quarter of each calendar year (27). Final data from each season on influenza illness, vaccine effectiveness, and vaccine coverage were incorporated into a model that estimated the annual impact of vaccination and the incremental benefit that would be achieved with increased coverage of current vaccines or with future vaccines with higher efficacy $(28,29)$. The model estimates that, from 2010-11 through 2015-16, a total of $26,808,150$ illnesses and 415,115 hospitalizations were prevented through seasonal influenza vaccination (30). Influenza vaccination was associated with reduced risk for laboratory-confirmed influenza-associated pediatric death (31).

In 2004-05, state and local public health and clinicians faced substantial challenges from a sudden decrease in expected influenza vaccine doses for the US market (2). Investments of the US government and vaccine manufacturers led to a diversified influenza vaccine supply and substantially more doses produced in more recent years. New formulations include quadrivalent, cell-based, recombinant, high-dose, and adjuvanted products (32). Universal recommendations for annual vaccination and more predictable supply resulted in more persons in the United States immunized against influenza. Data from the National Health Interview Survey suggest the proportion of all US adults receiving influenza vaccine increased from $27.4 \%$ in $2005-06$ (33) to $44.8 \%$ in $2014-15$ (34).

Annual measurements of vaccine effectiveness show major limitations in protection by current vaccines. New questions concern possible lower effectiveness after sequential vaccination and lower effectiveness against influenza $\mathrm{A}(\mathrm{H} 3 \mathrm{~N} 2)$ virus. Public health practitioners and clinicians thus face new challenges, despite ample supply, promoting the imperfect vaccines currently available. Although researchers focus on development of universal influenza vaccines, incremental improvements, such as cell-derived vaccine candidate viruses, which can avoid egg-adapted vaccine virus changes, offer promise in the interim.

\section{Strengthening Health Protection and Response}

In conjunction with national strategies for pandemic preparedness issued by the US government $(35,36)$, CDC worked with state and local health departments, clinicians, nongovernmental organizations, and global partners to strengthen readiness for avian and pandemic influenza. Exercises helped ready public health authorities for pandemics and other biologic threats, including assessment of community mitigation strategies. Public engagement efforts conducted in 2005-2009 permitted planners to incorporate values of citizens into prioritization for scarce vaccine supplies and led to development of strategies to reach workers in critical infrastructure fields (37). CDC supported strengthened detection (e.g., enhanced diagnostic and surveillance systems) and improved response capabilities for influenza $(38,39)$. Investments and technical assistance also focused on upgrading capacities within state and local public health agencies in the United States and ministries of health in other countries to address other emerging or severe respiratory pathogens.

On April 21, 2009, CDC reported 2 human cases of respiratory illness in southern California caused by a novel influenza virus that had a previously unseen combination of genes that originated from viruses circulating previously in pigs, birds, and humans $(40,41)$. Additional cases in California, Texas, New York, and Mexico led to recognition of the 2009 influenza A(H1N1) pandemic. Elderly populations had some cross-protection against the virus, but children and younger adults were disproportionately affected (42). Facilitated by preparedness investments, the influenza laboratory of NCIRD was able to adapt a PCR test for detection of the pandemic H1N1 virus, obtain Emergency Use Authorization from the US Food and Drug Administration, and rapidly ship new diagnostic test kits to states and 153 countries (38). CDC and its partners rapidly prepared a candidate vaccine virus so that the multiple steps of vaccine manufacturing could get under way quickly. The pandemic response effort of CDC supported epidemiologic and virologic investigations, adapted the centralized vaccine distribution system used for the Vaccines for Children Program, and made 330,000 shipments of monovalent influenza vaccine. CDC worked with state and local health departments to support vaccination at high-throughput public clinics, private provider offices, occupational clinics and, eventually, pharmacies. During October-December 2009, more than 80 million persons in the United States received the monovalent H1N1 vaccine. The pandemic response incorporated risk communication strategies, frequent media briefs, and messages shared through trusted community-based partners to reach diverse populations. The initial response included large numbers of school closures, which were highly disruptive. Updated policy advised more limited use of school dismissals.

Unfortunately, large amounts of vaccine were not available until several weeks after the peak of the fall pandemic wave. The 2009 H1N1 pandemic virus caused lower overall severe illness in the fall of 2009 than had been expected. However, in 2014-15, circulation of a drifted influenza $\mathrm{A}(\mathrm{H} 3 \mathrm{~N} 2)$ virus caused substantially more severe disease, resulting in an estimated 707,155 hospitalizations $(28,30)$. 
During its first decade, NCIRD also addressed several novel respiratory pathogens, including enterovirus D68 and concurrent increases in acute flaccid myelitis in children. Emergence of virulent avian influenza A(H7N9) virus in China in 2013 prompted intensified surveillance and prepandemic vaccine investments. Evolution of viruses and geographic spread has further increased concern (43). During 2012-2015, sporadic cases and outbreaks of severe respiratory illness caused by the newly recognized Middle East respiratory syndrome coronavirus were detected in Saudi Arabia and elsewhere on the Arabian Peninsula. As occurred for severe acute respiratory syndrome coronavirus and Ebola virus, transmission in hospital settings affected patients and healthcare workers (44). NCIRD coordinated agency preparedness and response to Middle East respiratory syndrome. When the virus was imported to Indiana and Florida in the United States by 2 healthcare workers who had been exposed in hospitals in Saudi Arabia, prompt detection and response included effective infection control and contact tracing. No further spread from these importations occurred.

\section{Global Vaccine-Preventable Disease Progress}

Vaccine-preventable disease control has benefited from longstanding efforts by the United Nations Children's Fund, the WHO Expanded Program on Immunization, and the Global Polio Eradication Initiative, among others. NCIRD collaborated with these and newer organizations, such as the Global Alliance for Vaccines and Immunization (Gavi), which supports new and underused vaccination in low-resource countries.

The first decade of NCIRD coincided with major progress in accelerated uptake of new or underused vaccines in developing countries. NCIRD epidemiologic and laboratory studies contributed to the evidence base in support of broader use of pneumococcal conjugate and rotavirus vaccines, and NCIRD staff played key leadership or technical roles in public-private partnerships, such as the Hib Initiative (45) and pneumococcal and rotavirus Accelerated Development and Introduction Plans (46), funded by Gavi, and provided laboratory and statistical support to the Meningitis Vaccine Project led by PATH (Seattle, WA, USA) and WHO. Use of Hib vaccine increased from 19 Gavi-supported countries in 2005 to all 73 by 2014 . Use of pneumococcal conjugate increased to 54 countries, and use of rotavirus vaccines increased to 37 countries (Figure 4). MenAfriVac, developed by Serum Institute of India with support from the Meningitis Vaccine Project, was administered in campaigns during 2010-2015 that reached 235 million persons within the African meningitis belt. These efforts have eliminated epidemics of group A meningococcal meningitis (47), although more recent outbreaks of group $\mathrm{C}$ meningococcal disease have occurred. During this period, NCIRD assisted ministries of health in assessing benefits of the newer vaccines $(46,48,49)$, as well as the occurrence and favorable benefit-risk ratio associated with intussusception after rotavirus vaccination (46).

Global eradication of polio has been a priority since 1988. During 2006-2015, polio transmission was interrupted in Egypt and India, and rapid response efforts halted outbreaks of imported polio in many counties in Africa, as well as in Tajikistan and the Middle East. By 2015, wild poliovirus continued to circulate in Afghanistan, Pakistan, and Nigeria, although annual case counts had decreased from 1,997 wild poliovirus cases in 2006 to 74 in 2015. NCIRD scientists led the Global Polio Eradication Initiative laboratory network, enhanced approaches to environmental monitoring, and assessed use of bivalent and monovalent oral polio vaccine and fractional doses of inactivated polio

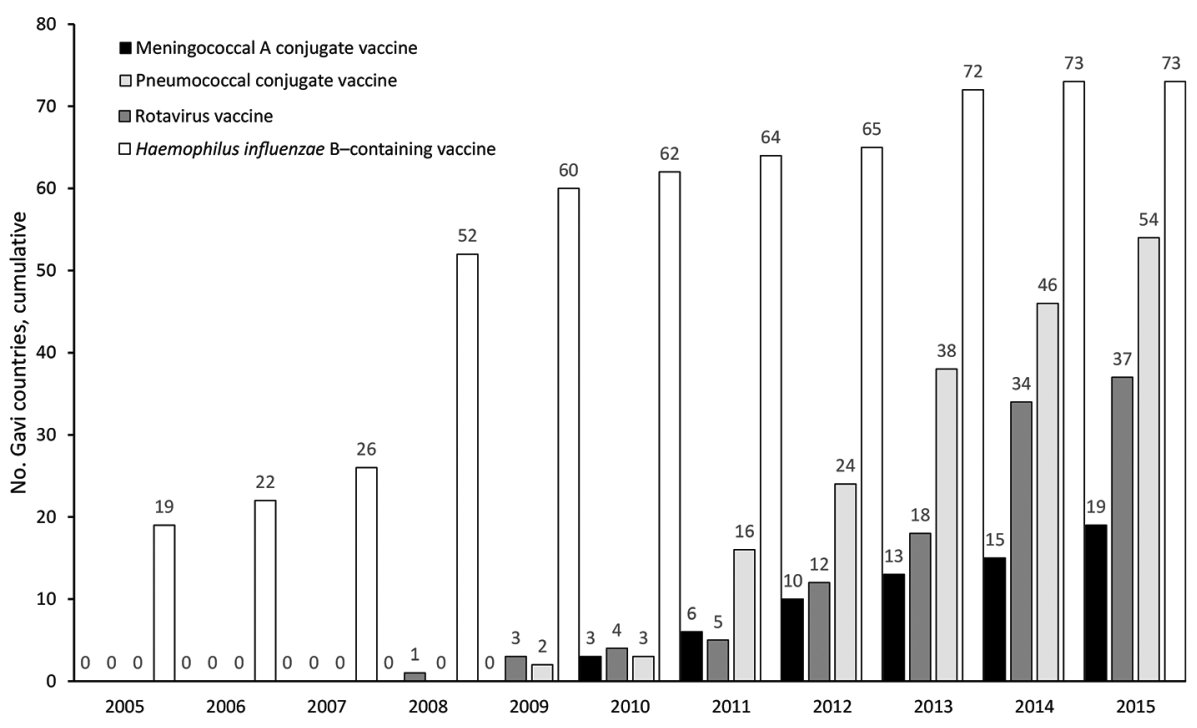

Figure 4. Cumulative number of Gavi-eligible countries using selected new or underused vaccines in routine programs, 2005-2015. Data were obtained from Gavi. Gavi, Global Alliance for Vaccines and Immunization. 
Progress in First 10 Years of the CDC NCIRD

vaccine as tools for achieving eradication. In 2011, the Global Immunization Division moved from NCIRD to the newly formed Center for Global Health to continue programmatic aspects of eradication and vaccine-preventable disease control. Laboratories at CDC for vaccine-preventable diseases, including polio and measles, remained in NCIRD. Strong collaboration between the Global Immunization Division and NCIRD has continued, as has sharing of the US experience with vaccine hesitancy with partners facing similar challenges in other regions.

\section{Ongoing Challenges}

Globalization and microbial adaptation continue to threaten disease control progress. Sustaining community acceptance is needed even once effective and safe interventions are available. Although technological improvements to laboratory detection, vaccine development and production, and information systems have been marked during the first decade of NCIRD, application to public health, including immunization and disease reporting, is slow. Business drivers to improvements in electronic health records and fragmentation of the public health enterprise (e.g., different immunization registries in each state) have limited progress. Another challenge has been lower than expected vaccine performance (e.g., acellular pertussis, live attenuated influenza vaccine). Development of influenza vaccines with broader protection is a priority, but their availability remains years away. Decreasing survey response rates threaten continuity of health monitoring, while the potential of big data for conditions requiring precise laboratory confirmation, such as respiratory pathogens, might be limited. The Global Health Security Agenda includes roadmaps and accountability metrics to strengthen response to emerging threats, but sustained governmental and private sector commitments to this effort will be essential.

\section{Conclusions}

Establishment of a center housing epidemiologic, laboratory, and program units related to vaccine-preventable and acute respiratory infectious disease provided a platform for strategic improvements to disease prevention and control that was timely given the influenza pandemic in 2009 , the changing epidemiology of vaccine-preventable diseases, and increased demands on the immunization system in the United States. NCIRD worked in concert with state and local public health, as well as with numerous global partners, to optimize use of available prevention tools, strengthen detection and control measures, and build the evidence base for the next generation of interventions, such as improved influenza vaccines and vaccines in development against respiratory syncytial virus. Pandemic influenza and Ebola showed that implementing vaccination or testing new countermeasures in the midst of epidemics is difficult. Global initiatives suggest that partnerships between public and private sectors, engaging scientific and programmatic perspectives, might achieve more impact than single-agency efforts.

As ministries of health in industrialized and resourcepoor countries increase attention to pandemic-prone respiratory infections and expand their immunization programs to address common endemic infectious diseases, organizational change similar to ours might be beneficial. However, organizational design cannot address or anticipate every issue, and will not eliminate the interdependence of programs or the value of collaboration across programs, sectors, and nations.

\section{Acknowledgments}

We thank Marjorie Sorrells for assistance with preparation of the manuscript; Hugh Green and Jessica Mullis for graphics support; and state, local, and academic public health partners for contributing to these advancements.

\section{About the Author}

Dr. Schuchat is Principal Deputy Director of CDC and was director of NCIRD during 2006-2015. She has served in other leadership posts, including acting CDC director (January-July 2017 and January-March 2018) and chief of the Respiratory Diseases Branch (1998-2005). She has also played key roles in CDC emergency responses, including the influenza A(H1N1) pandemic response in 2009, the severe acute respiratory syndrome outbreak in Beijing in 2003, and the bioterrorist anthrax response in 2001. Her research interests include prevention effectiveness, vaccine evaluations, and global health.

\section{References}

1. Beigel JH, Farrar J, Han AM, Hayden FG, Hyer R, de Jong MD, et al.; Writing Committee of the World Health Organization (WHO) Consultation on Human Influenza A/H5 . Avian influenza A (H5N1) infection in humans. N Engl J Med. 2005;353:1374-85. http://dx.doi.org/10.1056/NEJMra052211

2. Centers for Disease Control and Prevention. Updated interim influenza vaccination recommendations - 2004-05 influenza season. MMWR Morb Mortal Wkly Rep. 2004;53:1183-4.

3. Clark TA. Changing pertussis epidemiology: everything old is new again. J Infect Dis. 2014;209:978-81. http://dx.doi.org/10.1093/ infdis/jiu001

4. Orenstein WA, Gellin BG, Beigi RH, Buck T, Despres S, LaRussa PS, et al.; National Vaccine Advisory Committee. Protecting the public's health: critical functions of the Section 317 Immunization Program-a report of the National Vaccine Advisory Committee. Public Health Rep. 2013;128:78-95. http://dx.doi.org/10.1177/003335491312800203

5. Molinari NM, Wolter KM, Skalland B, Montgomery R, Khare M, Smith PJ, et al. Quantifying bias in a health survey: modeling total survey error in the national immunization survey. Stat Med. 2011;30:505-14. 
6. Ahmed F, Temte JL, Campos-Outcalt D, Schünemann HJ; ACIP Evidence Based Recommendations Work Group (EBRWG). Methods for developing evidence-based recommendations by the Advisory Committee on Immunization Practices (ACIP) of the US Centers for Disease Control and Prevention (CDC). Vaccine. 2011;29:9171-6. http://dx.doi.org/10.1016/j.vaccine.2011.08.005

7. Walton LR, Orenstein WA, Pickering LK. The history of the United States Advisory Committee on Immunization Practices (ACIP). Vaccine. 2015;33:405-14. http://dx.doi.org/10.1016/ j.vaccine.2014.09.043

8. Hill HA, Elam-Evans LD, Yankey D, Singleton JA, Dietz V. Vaccination coverage among children aged 19-35 months - United States, 2015. MMWR Morb Mortal Wkly Rep. 2016;65:1065-71. http://dx.doi.org/10.15585/mmwr.mm6539a4

9. Sugerman DE, Barskey AE, Delea MG, Ortega-Sanchez IR, Bi D, Ralston KJ, et al. Measles outbreak in a highly vaccinated population, San Diego, 2008: role of the intentionally undervaccinated. Pediatrics. 2010;125:747-55. http://dx.doi.org/ 10.1542/peds.2009-1653

10. Schuchat A, Fiebelkorn AP, Bellini W. Measles in the United States since the millennium: perils and progress in the postelimination era. Microbiol Spectr. 2016;4.

11. Whitney CG, Zhou F, Singleton J, Schuchat A; Centers for Disease Control and Prevention. Benefits from immunization during the vaccines for children program era—United States, 1994-2013. MMWR Morb Mortal Wkly Rep. 2014;63:352-5.

12. Zhou F, Shefer A, Wenger J, Messonnier M, Wang LY, Lopez A, et al. Economic evaluation of the routine childhood immunization program in the United States, 2009. Pediatrics. 2014;133:577-85. http://dx.doi.org/10.1542/peds.2013-0698

13. Self WH, Williams DJ, Zhu Y, Ampofo K, Pavia AT, Chappell JD, et al. Respiratory viral detection in children and adults: comparing asymptomatic controls and patients with communityacquired pneumonia. J Infect Dis. 2016;213:584-91. http://dx.doi.org/10.1093/infdis/jiv323

14. Jain S, Williams DJ, Arnold SR, Ampofo K, Bramley AM, Reed C, et al.; CDC EPIC Study Team. Community-acquired pneumonia requiring hospitalization among US children. N Engl J Med. 2015;372:835-45. http://dx.doi.org/10.1056/ NEJMoa 1405870

15. Jain S, Self WH, Wunderink RG, Fakhran S, Balk R, Bramley AM, et al.; CDC EPIC Study Team. Community-acquired pneumonia requiring hospitalization among US adults. N Engl J Med. 2015;373:415-27. http://dx.doi.org/10.1056/NEJMoa1500245

16. Wonodi CB, Deloria-Knoll M, Feikin DR, DeLuca AN, Driscoll AJ, Moïsi JC, et al.; Pneumonia Methods Working Group and PERCH Site Investigators. Evaluation of risk factors for severe pneumonia in children: the Pneumonia Etiology Research for Child Health study. Clin Infect Dis. 2012;54(Suppl 2):S124-31. http://dx.doi.org/10.1093/cid/cir1067

17. Diaz MH, Waller JL, Napoliello RA, Islam MS, Wolff BJ, Burken DJ, et al. Optimization of multiple pathogen detection using the TaqMan Array Card: application for a population-based study of neonatal infection. PLoS One. 2013;8:e66183. http://dx.doi.org/10.1371/journal.pone.0066183

18. Murphy SL, Xu J, Kochanek KD, Curtin SC, Arias E. Deaths: final data for 2015. Natl Vital Stat Rep. 2017;66:1-75.

19. Griffin MR, Zhu Y, Moore MR, Whitney CG, Grijalva CG. US hospitalizations for pneumonia after a decade of pneumococcal vaccination. N Engl J Med. 2013;369:155-63. http://dx.doi.org/ 10.1056/NEJMoa1209165

20. Lexau CA, Lynfield R, Danila R, Pilishvili T, Facklam R, Farley MM, et al.; Active Bacterial Core Surveillance Team. Changing epidemiology of invasive pneumococcal disease among older adults in the era of pediatric pneumococcal conjugate vaccine. JAMA. 2005;294:2043-51. http://dx.doi.org/10.1001/jama.294.16.2043
21. Heffernan RT, Barrett NL, Gallagher KM, Hadler JL, Harrison LH, Reingold AL, et al. Declining incidence of invasive Streptococcus pneumoniae infections among persons with AIDS in an era of highly active antiretroviral therapy, 1995-2000. J Infect Dis. 2005;191:2038-45. http://dx.doi.org/10.1086/430356

22. Nuorti JP, Butler JC, Farley MM, Harrison LH, McGeer A, Kolczak MS, et al.; Active Bacterial Core Surveillance Team. Cigarette smoking and invasive pneumococcal disease. N Engl J Med. 2000;342:681-9. http://dx.doi.org/10.1056/ NEJM200003093421002

23. Musher DM, Abers MS, Bartlett JG. Evolving understanding of the causes of pneumonia in adults, with special attention to the role of pneumococcus. Clin Infect Dis. 2017;65:1736-44. http://dx.doi.org/10.1093/cid/cix549

24. Wang TW, Kenemer B, Tynan MA, Singh T, King B. Consumption of combustible and smokeless tobacco-United States, 2000-2015. MMWR Morb Mortal Wkly Rep. 2016;65:1357-63. http://dx.doi.org/10.15585/mmwr.mm6548a1

25. Ward BW, Clarke TC, Nugent CN, Schiller JS. Early release of selected estimates based on data from the 2015 National Health Interview Survey. National Center for Health Statistics, May 2016 [cited 2018 Feb 22]. http://www.cdc.gov/nchs/nhis.htm

26. Tomczyk S, Bennett NM, Stoecker C, Gierke R, Moore MR, Whitney CG, et al.; Centers for Disease Control and Prevention. Use of 13-valent pneumococcal conjugate vaccine and 23-valent pneumococcal polysaccharide vaccine among adults aged $\geq 65$ years: recommendations of the Advisory Committee on Immunization Practices (ACIP). MMWR Morb Mortal Wkly Rep. 2014;63:822-5.

27. Flannery B, Chung JR, Thaker SN, Monto AS, Martin ET, Belongia EA, et al. Interim estimates of 2016-17 seasonal influenza vaccine effectiveness-United States, February 2017. MMWR Morb Mortal Wkly Rep. 2017;66:167-71. http://dx.doi.org/10.15585/mmwr.mm6606a3

28. Reed C, Chaves SS, Daily Kirley P, Emerson R, Aragon D, Hancock EB, et al. Estimating influenza disease burden from population-based surveillance data in the United States. PLoS One. 2015;10:e0118369. http://dx.doi.org/10.1371/ journal.pone. 0118369

29. Kostova D, Reed C, Finelli L, Cheng PY, Gargiullo PM, Shay DK, et al. Influenza illness and hospitalizations averted by influenza vaccination in the United States, 2005-2011. PLoS One. 2013;8:e66312. http://dx.doi.org/10.1371/journal.pone.0066312

30. Rolfes MA, Foppa IM, Garg S, Flannery B, Brammer L, Singleton JA, et al. Estimated influenza illnesses, medical visits, hospitalizations, and deaths averted by vaccination in the United States, December 9, 2016 [cited 2017 Aug 31]. https://www.cdc.gov/flu/about/disease/2015-16.htm.

31. Flannery B, Reynolds SB, Blanton L, Santibanez TA, O'Halloran A, Lu PJ, et al. Influenza vaccine effectiveness against pediatric deaths: 2010-2014. Pediatrics. 2017;139:e20164244. http://dx.doi.org/10.1542/peds.2016-4244

32. Grohskopf LA, Sokolow LZ, Broder KR, Olsen SJ, Karron RA, Jernigan DB, et al. Prevention and control of seasonal influenza with vaccines. MMWR Recomm Rep. 2016;65:1-54. http://dx.doi.org/10.15585/mmwr.rr6505a1

33. Lu PJ, Singleton JA, Euler GL, Williams WW, Bridges CB. Seasonal influenza vaccination coverage among adult populations in the United States, 2005-2011. Am J Epidemiol. 2013;178:147887. http://dx.doi.org/10.1093/aje/kwt158

34. Williams WW, Lu PJ, O'Halloran A, Kim DK, Grohskopf LA, Pilishvili T, et al. Surveillance of vaccination coverage among adult populations - United States, 2015. MMWR Surveill Summ. 2017;66:1-28. http://dx.doi.org/10.15585/mmwr.ss6611a1

35. US Homeland Security Council. National strategy for pandemic influenza. Washington (DC): US Homeland Security Council, 
2005 [cited 2018 Feb 22]. http://permanent.access.gpo.gov/ lps64971/nspi.pdf

36. US Department of Health and Human Services; HHS pandemic influenza plan. Washington (DC): The Department; 2005 [cited 2018 Feb 22]. http://www.hhs.gov/pandemicflu/plan/pdf/ HHSPandemicInfluenzaPlan.pdf

37. Keystone Policy Center. Citizen voices on pandemic flu choices: a report of the public engagement project on pandemic influenza. Washington (DC): US Department of Health and Human Services, 2005 [cited 2018 Feb 22]. https://archive.hhs.gov/nvpo/PEPPPI/ PEPPPICompleteFinalReport.pdf

38. Jernigan DB, Lindstrom SL, Johnson JR, Miller JD, Hoelscher M, Humes R, et al. Detecting 2009 pandemic influenza A (H1N1) virus infection: availability of diagnostic testing led to rapid pandemic response. Clin Infect Dis. 2011;52(Suppl 1):S36-43.

http://dx.doi.org/10.1093/cid/ciq020

39. Kennedy P, Aden T, Cheng PY, Moen A. Measuring influenza laboratory capacity: use of a tool to measure improvements. BMC Infect Dis. 2017;17:431. http://dx.doi.org/10.1186/ s12879-017-2521-7

40. Centers for Disease Control and Prevention. Swine influenza A (H1N1) infection in two children-Southern California, MarchApril 2009. MMWR Morb Mortal Wkly Rep. 2009;58:400-2.

41. Garten RJ, Davis CT, Russell CA, Shu B, Lindstrom S, Balish A, et al. Antigenic and genetic characteristics of swine-origin 2009 $\mathrm{A}(\mathrm{H} 1 \mathrm{~N} 1)$ influenza viruses circulating in humans. Science. 2009;325:197-201. http://dx.doi.org/10.1126/science.1176225

42. Shrestha SS, Swerdlow DL, Borse RH, Prabhu VS, Finelli L, Atkins CY, et al. Estimating the burden of 2009 pandemic influenza A (H1N1) in the United States (April 2009-April 2010). Clin Infect Dis. 2011;52(Suppl 1):S75-82. http://dx.doi.org/10.1093/cid/ciq012

43. Kile JC, Ren R, Liu L, Greene CM, Roguski K, Iuliano AD, et al. Update: increase in human infections with novel Asian lineage avian influenza A(H7N9) viruses during the fifth epidemic - China, October 1, 2016-August 7, 2017. MMWR Morb Mortal Wkly Rep. 2017;66:928-32. http://dx.doi.org/10.15585/mmwr.mm6635a2

44. Hastings DL, Tokars JI, Abdel Aziz IZ, Alkhaldi KZ, Bensadek AT, Alraddadi BM, et al. Outbreak of Middle East respiratory syndrome at tertiary care hospital, Jeddah, Saudi Arabia, 2014. Emerg Infect Dis. 2016;22:794-801. http://dx.doi.org/10.3201/eid2205.151797

45. Hajjeh R, Mulholland K, Schuchat A, Santosham M. Progress towards demonstrating the impact of Haemophilus influenzae type b conjugate vaccines globally. J Pediatr. 2013;163(Suppl):S1-3. http://dx.doi.org/10.1016/j.jpeds.2013.03.022

46. Patel MM, Clark AD, Glass RI, Greenberg H, Tate J, Santosham M, et al. Broadening the age restriction for initiating rotavirus vaccination in regions with high rotavirus mortality: benefits of mortality reduction versus risk of fatal intussusception. Vaccine. 2009;27:2916-22. http://dx.doi.org/10.1016/j.vaccine.2009.03.016

47. Shrivastava SR, Shrivastava PS, Ramasamy J. Nearing elimination of meningitis A from the African "meningitis belt" using meningococcal A conjugate vaccine. Germs. 2016;6:66-7. http://dx.doi.org/10.11599/germs.2016.1091

48. Richardson V, Parashar U, Patel M. Childhood diarrhea deaths after rotavirus vaccination in Mexico. N Engl J Med. 2011;365:772-3. http://dx.doi.org/10.1056/NEJMc1100062

49. Kristiansen PA, Ba AK, Ouédraogo AS, Sanou I, Ouédraogo R, Sangaré L, et al. Persistent low carriage of serogroup A

Neisseria meningitidis two years after mass vaccination with the meningococcal conjugate vaccine, MenAfriVac. BMC Infect Dis. 2014;14:663. http://dx.doi.org/10.1186/s12879-014-0663-4

Address for correspondence: Anne Schuchat, Centers for Disease Control and Prevention, 1600 Clifton Rd NE, Mailstop D14, Atlanta, GA

30329-4027, USA, email: aschuchat@cdc.gov

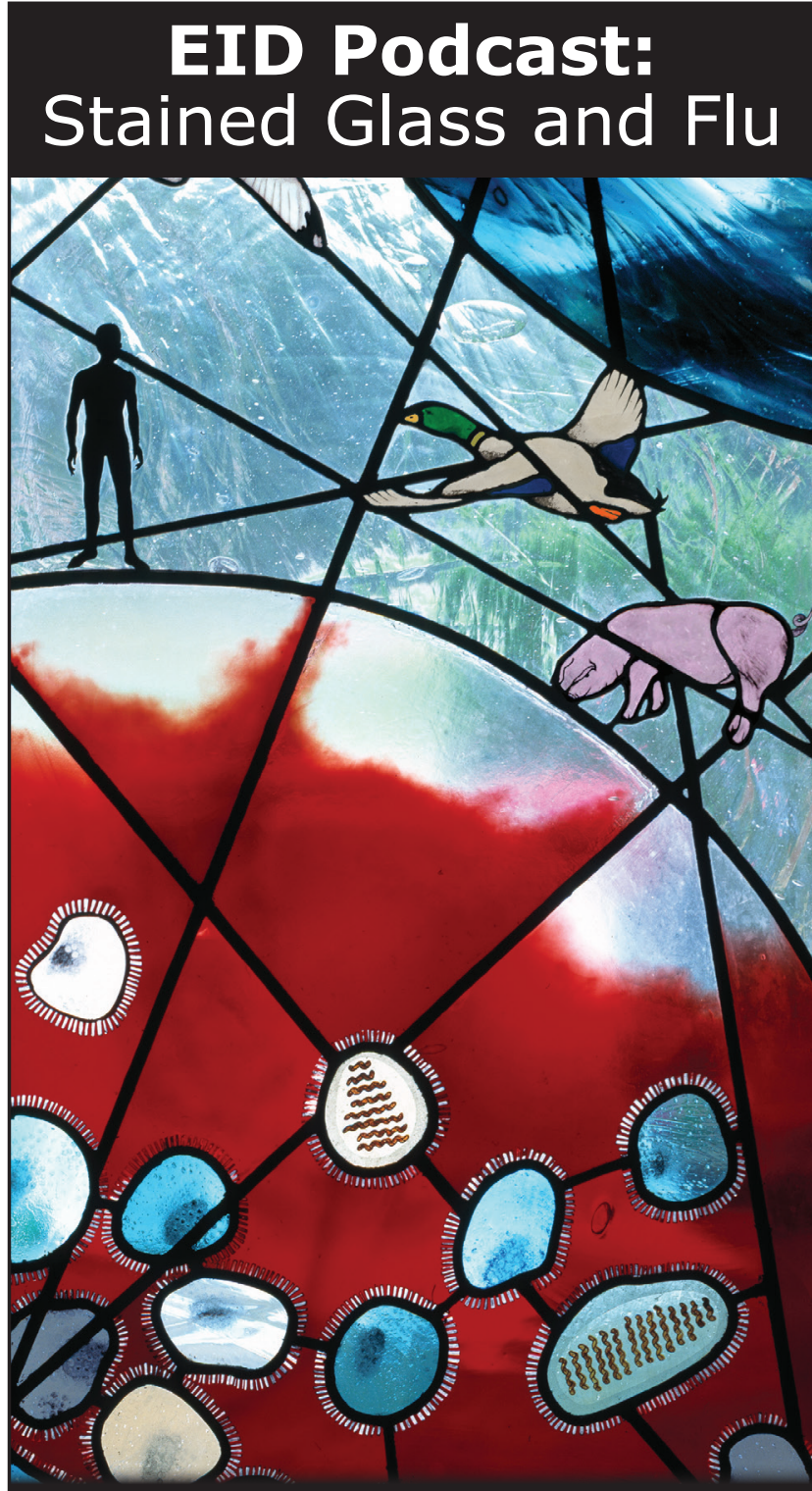

The work of art shown here depicts the interrelationship of human, animal, and environmental health.

Stained-glass windows have been appreciated for their utility and splendor for more than 1,000 years, and this engaging work of art by stained glass artist Jenny Hammond reminds us that influenza A viruses-which can be easily spread between animals and humans, use various host species, and exist in many different environments-remain an enduring and global health concern.

\section{Visit our website to listen:}

\section{EMEREING} INFECTIOUS DISEASES https://www2c.cdc.gov/

podcasts/player.

asp?f $=\mathbf{8 6 4 4 9 5 0}$ 